\title{
Aberrant methylation of NPY, PENK, and WIF1 as a promising marker for blood-based diagnosis of colorectal cancer
}

Jean-Pierre Roperch ${ }^{1 * \dagger}$, Roberto Incitti ${ }^{2 \dagger}$, Solène Forbin ${ }^{3}$, Floriane Bard ${ }^{3}$, Hicham Mansour ${ }^{2,3}$, Farida Mesli ${ }^{4}$, Isabelle Baumgaertner ${ }^{5}$, Francesco Brunetti ${ }^{6}$ and Iradj Sobhani $i^{3,4^{*}}$

\begin{abstract}
Background: DNA methylation is a well-known epigenetic mechanism involved in epigenetic gene regulation. Several genes were reported hypermethylated in CRC, althought no gene marker was proven to be individually of sufficient sensitivity or specificity in routine clinical practice. Here, we identified novel epigenetic markers and assessed their combined use for diagnostic accuracy.

Methods: We used methylation arrays on samples from several effluents to characterize methylation profiles in CRC samples and controls, as established by colonoscopy and pathology findings, and selected two differentially methylated candidate epigenetic genes (NPY, PENK). To this gene panel we added WIF, on the basis of being reported in literature as silenced by promoter hypermethylation in several cancers, including CRC. We measured their methylation degrees by quantitative multiplex-methylation specific PCR (QM-MSP) on 15 paired carcinomas and adjacent non-cancerous colorectal tissues and we subsequently performed a clinical validation on two different series of 266 serums, subdivided in 32 CRC, 26 polyps, 47 other cancers and 161 with normal colonoscopy. We assessed the results by receiver operating characteristic curve (ROC), using cumulative methylation index (CMI) as variable threshold.

Results: We obtained CRC detection on tissues with both sensitivity and specificity of $100 \%$. On serum CRC samples, we obtained sensitivity/specificity values of, e.g., $87 \% / 80 \%, 78 \% / 90 \%$ and $59 \% / 95 \%$, and negative predictive value/positive predictive value figures of $97 \% / 47 \%, 95 \% / 61 \%$ and $92 \% / 70 \%$. On serum samples from other cancers we obtained sensitivity/specificity of, e.g, 89\%/25\%, 43\%/80\% and 28\%/91\%.

Conclusions: We showed the potential of NPY, PENK, and WIF1 as combined epigenetic markers for CRC diagnosis, both in tissue and serum and tested their use as serum biomarkers in other cancers. We optimized a QM-MSP for simultaneously quantifying their methylation levels. Our assay can be an effective blood test for patients where CRC risk is present but difficult to assess (e.g. mild symptoms with no CRC family history) and who would therefore not necessarily choose to go for further examination. This panel of markers, if validated, can also be a cost effective screening tool for the detection of asymptomatic cancer patients for colonoscopy.
\end{abstract}

Keywords: Colorectal cancer, Circulating DNA methylation, QM-MSP, Epigenetic markers

\footnotetext{
*Correspondence: jp.roperch@profilome-sas.com; iradj.sobhani@hmn.aphp.fr

${ }^{\dagger}$ Equal contributors

${ }^{1}$ Profilome SAS, Paris Biotech 24 rue du Faubourg St Jacques, Paris 75014,

France

${ }^{3}$ Laboratoire d'Investigation Clinique (LIC), Henri Mondor Hospital \& University

Paris-Est, Créteil, France

Full list of author information is available at the end of the article
} 


\section{Background}

Colorectal cancer (CRC) is one of the most frequent malignant diseases worldwide $[1,2]$ yielding high rate mortality [3]. Early diagnosis of CRC is required to increase the survival rates of patients [4]. Currently, endoscopic examination of the colon is the standard for CRC diagnosis. However, this procedure is invasive, unpleasant, carries a number of associated risks of morbidity and mortality and is inaccurate for screening purposes in the average risk populations [5]. Fecal tests (e.g. occult blood test-FOBT and Fecal altered DNA tests) seeking to detect presence of colorectal tumors are available as a pre-colonoscopy test [6-9]. Although FOBTs can significantly reduce mortality due to CRCs $[10,11]$, these tests are flawed by higher rates of false-negatives and false-positives as referred to colonoscopy [12]. In this context, new specific CRC markers for diagnosis of CRC are needed. Over the last decade, aberrant methylation of $\mathrm{CpG}$ islands in the promoter and exon 1 regions of tumor suppressor genes is common mechanism in human cancers [13-15] and suggested that measurement of the methylation level can aid diagnosis [16-18].

In the present study, we propose a panel of tumorspecific methylation genes (NPY, PENK, and WIF1) which in combination show a potential as epigenetic markers for the colorectal cancer diagnosis. We have developed a quantitative multiplex-methylation specific PCR (QM-MSP) to quantitate cumulative methylation of these markers in tissue and serum samples. On serum sample, we suggest that our QM-MSP can help in preselecting the patients having mild symptoms or without CRC family history for colonoscopy and potentially, if validated, for the screening of colorectal cancer.

\section{Methods}

\section{Human samples}

Human samples were collected from individuals referred to the gastrointestinal endoscopy units of several academic hospitals (Table 1). Patients gave informed consent (registered under 04-2004 and revised as CPP-IDF IX-11-019 by CPP, consultative ethical committee in the Ile de France-Est medical district), blood samples were collected prior to colonoscopy. Endoscopy and pathology reports were recorded on anonymized files. Tumor biopsies were obtained under colonoscopy procedures or by using surgical resections. Tissue samples have been frozen at $-80^{\circ} \mathrm{C}$ until DNA was extracted. For each individual, samples were also paraffin-embedded and conserved for pathology analyses. In all cases, samples of normal homologous colonic tissues were similarly conserved. They were used for microsatellite instability analysis and the KRAS mutations which are routinely performed in our hospital before undergoing methylation testing and tumor staging was determined according to the TNM-classification (Additional file 1: Table S1).
Table 1 Patients characteristics of clinical studies

\begin{tabular}{|c|c|c|c|}
\hline & Characteristic & Patients & Controls \\
\hline \multirow[t]{10}{*}{ Tissue } & & $n=15^{*}$ & \\
\hline & Sex & & \\
\hline & Male & 12 & \\
\hline & Female & 3 & \\
\hline & Age (yr) & & \\
\hline & Mean $\pm S D$ & $70.4 \pm 13.5$ & \\
\hline & Range & $48-93$ & \\
\hline & Stage & & \\
\hline & $|/| \mid$ & $6(1 / 5)$ & \\
\hline & III/IV & $9(5 / 4)$ & \\
\hline \multirow[t]{10}{*}{ Serum } & & $n=32$ & $n=161$ \\
\hline & Sex & & \\
\hline & Male & 21 & 86 \\
\hline & Female & 11 & 75 \\
\hline & Age & & \\
\hline & Mean \pm SD & $67.9 \pm 12.9$ & $59.1 \pm 16.5$ \\
\hline & Range & $36-94$ & 18-94 \\
\hline & Stage & & \\
\hline & $|/| \mid$ & $6(2 / 4)$ & $\mathrm{Na}$ \\
\hline & III/IV & $26(7 / 19)$ & $\mathrm{Na}$ \\
\hline
\end{tabular}

*In total 30 tisue samples corresponding to 15 CRC and 15 normal homologous tissues from 15 CRC patients were analyzed. Na: not applicable.

\section{Description of the clinical study}

First, a comprehensive DNA methylation profiling was performed on DNA from 30 tissues, stools and serum samples using Illumina goldengate methylation arrays that contain 1,505 markers (CpG loci) within 807 cancer-related genes (Illumina, CA). We selected NPY, PENK on the basis of their hypermethylation and their power to discriminative normal from CRC patients. Secondly, these candidate genes, together with WIF1gene that we selected based on evidence from literature [19-31], were evaluated in a multiplex assay on an additional $15 \mathrm{normal} /$ cancer paired colonic tissues. Thirdly, validations of the multiplex assay were carried out on the two independent series of sera (Table 2). Series 1 contained 49 serum samples including 9 patients with CRC, 10 patients with large polyp adenomatous (1 cm in diameter or more) at colonoscopy with 30 individuals with normal colonoscopy. Series 2 validation was carried out on 170 serum samples from 23 patients presenting with CRC, 16 patients with large polyp adenomatous, and 131 control individuals with tumor-free at colonoscopy (Figure 1). In the Series 3, we assayed 47 patients suffering from a digestive or extra digestive tumor other than CRC such as breast, prostate, kidney, bladder, liver, esophagus, pancreas, cholangiocarcinoma and stomach cancers. 
Table 2 Clinicopathologic characteristics in serum samples of patients with CRC and healthy control

\begin{tabular}{|c|c|c|c|c|}
\hline & Characteristic & CRC & Polyps & Controls \\
\hline \multirow[t]{10}{*}{ Series 1} & & $n=9$ & $n=10$ & $n=30$ \\
\hline & Sex & & & \\
\hline & Male & 3 & 6 & 15 \\
\hline & Female & 6 & 4 & 15 \\
\hline & Age & & & \\
\hline & Mean \pm SD & $66.1 \pm 17.2$ & $71.5 \pm 11.8$ & $62.1 \pm 17.3$ \\
\hline & Range & $36-94$ & $56-91$ & $22-91$ \\
\hline & Stage & & & \\
\hline & $|/| \mid$ & $4(1 / 3)$ & $\mathrm{Na}$ & $\mathrm{Na}$ \\
\hline & III/IV & $5(1 / 4)$ & $\mathrm{Na}$ & $\mathrm{Na}$ \\
\hline \multirow[t]{10}{*}{ Series 2} & & $n=23$ & $n=16$ & $n=131$ \\
\hline & Sex & & & \\
\hline & Male & 18 & 10 & 71 \\
\hline & Female & 5 & 6 & 60 \\
\hline & Age & & & \\
\hline & Mean \pm SD & $68.6 \pm 11.2$ & $61.8 \pm 9.2$ & $58.5 \pm 16.3$ \\
\hline & Range & $51-84$ & $52-85$ & $18-94$ \\
\hline & Stage & & & \\
\hline & |/II & $2(1 / 1)$ & $\mathrm{Na}$ & $\mathrm{Na}$ \\
\hline & III/IV & $21(6 / 15)$ & $\mathrm{Na}$ & $\mathrm{Na}$ \\
\hline \multirow[t]{10}{*}{ Series $1+2$ pooled } & & $n=32$ & $n=26$ & $n=161$ \\
\hline & Sex & & & \\
\hline & Male & 21 & 16 & 86 \\
\hline & Female & 11 & 10 & 75 \\
\hline & Age & & & \\
\hline & Mean \pm SD & $67.9 \pm 12.9$ & $65.5 \pm 11.1$ & $59.1 \pm 16.5$ \\
\hline & Range & $36-94$ & $52-91$ & $18-94$ \\
\hline & Stage & & & \\
\hline & $|/| \mid$ & $6(2 / 4)$ & $\mathrm{Na}$ & $\mathrm{Na}$ \\
\hline & III/IV & $26(7 / 19)$ & $\mathrm{Na}$ & $\mathrm{Na}$ \\
\hline
\end{tabular}

Na: not applicable.

\section{DNA isolation and bisulfite modification}

DNA was isolated from colonic tissues and stool samples by using a QIAamp DNA Mini Kit (Qiagen), and a QiAamp DNA stool mini kit (Qiagen), respectively. DNAs were isolated by using a ZR Serum DNA kit (Zymo Research) according to the manufacturer's protocol and were stored at $-20^{\circ} \mathrm{C}$ until methylation quantification after concentrations were performed using the Eppendorf BioPhotometer. Bisulfite treatment was adopted to transform unmethylated cytosine nucleotides into thymidine without changing methylated cytosines. This was carried out after DNA was chemically modified with sodium bisulfite at $50^{\circ} \mathrm{C}$ in the dark for 16 hours by using an EZ DNA Methylation kit (Zymo Research).

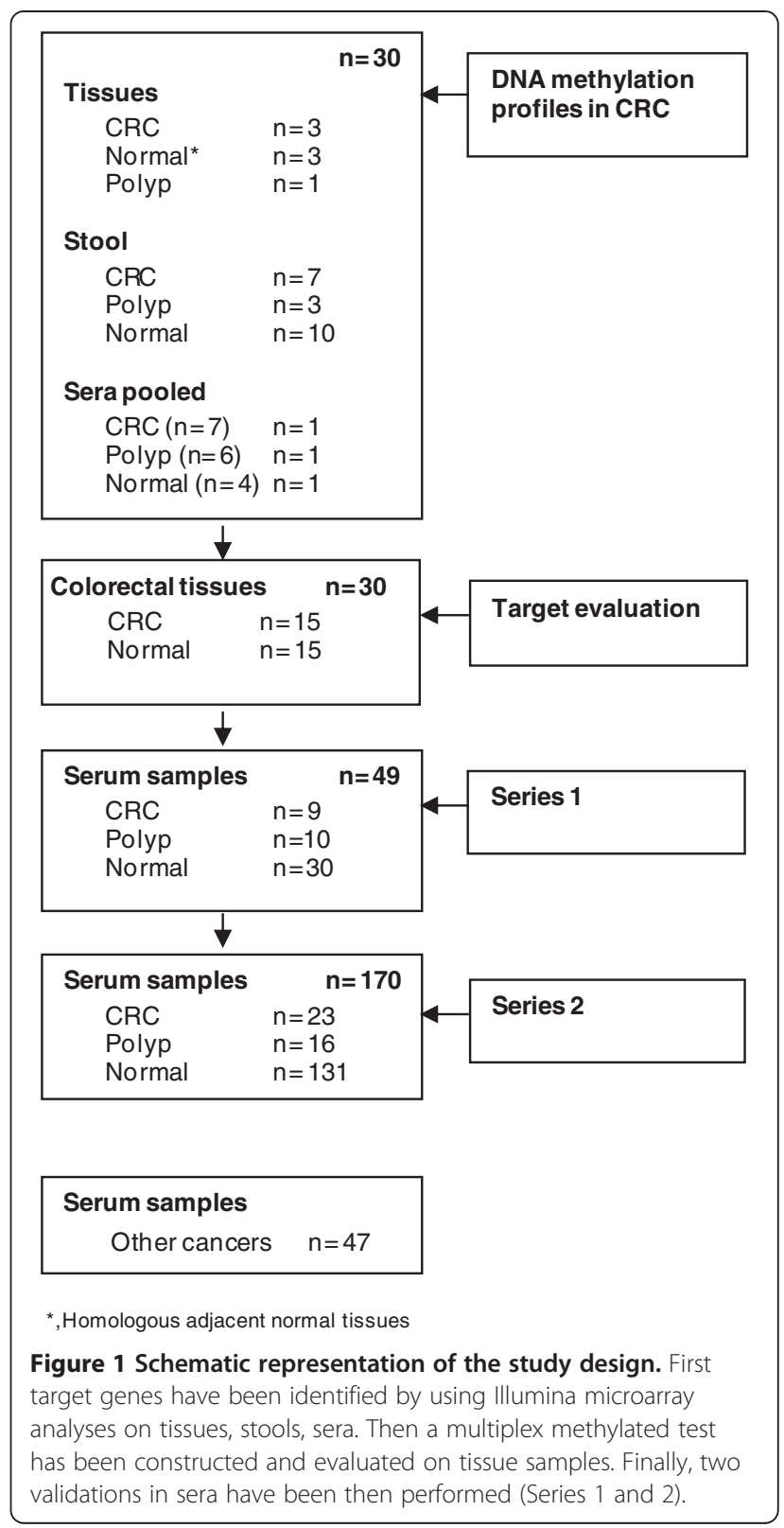

\section{Quantitative methylation-specific PCR amplification}

Modified DNA was analyzed by QS-MSP (quantitative singleplex-methylation specific PCR), and the QM-MSP (quantitative multiplex-methylation specific PCR). All PCR reactions were performed using an ABI prism $7900 \mathrm{HT}$ sequence detector (Applied Biosystems). For each PCR run, a master-mix was prepared, primers and probes for WIF1, NPY and PENK have been designed, and a primer/ probe set of albumin not containing CpG sites was used for normalizing the DNA amounts (Additional file 2: Table S2). The thermal cycling conditions included an initial denaturizing step at $95^{\circ} \mathrm{C} 48$ cycles for $15 \mathrm{~s}$ and at $60^{\circ} \mathrm{C}$ for $1 \mathrm{~min}$. Bisulfite methylated DNA (Zymo Research) was used as calibrator and positive control. DNA free 
distilled water was used as negative control. The relative level of methylation was determined by the $2^{-\Delta \Delta \mathrm{Ct}}$ method as described in supplementary data and the efficiency of reactions was determined by plotting in logarithmic scale the amounts of methylated DNA versus the corresponding Cts (cycle threshold) as baseline curves of the genes.

\section{Bisulfite genomic sequencing}

The PCR products of albumin, NPY, PENK, and WIF1 genes were purified before submission to the sequencing process of both strands by using BigDye Terminator Cycle Sequencing kit (Applied Biosystems) according to the manufacturer's instructions. The sequence reactions were run and analyzed on an ABI 3100 Genetic Analyzer (Applied Biosystems).

\section{DNA methylation profiling using Illumina Goldengate methylation bead arrays}

$500 \mathrm{ng}$ of bisulfite-converted DNA were probed on the Illumina Goldengate Methylation Cancer Panel I. A total of 30 DNA samples were assayed on the Illumina platform. Totally, there were seven tissue samples (3 colon cancer tissue, 1 large polyp tissue and 3 paired adjacent normal tissues), 20 stools samples (7 CRC patients, 3 individuals with large polyp adenomatous and 10 individuals with normal colonoscopy), and three pools of their serum DNA samples including colon cancer patients, patients with polyp adenomatous and individuals with normal colonoscopy. The values for each CpG site as a value in the range of $0-100.0 \%$ of methylation after subtracting background of negative controls on the array and taking the ratio of the methylated signal intensity to the sum of both methylated and unmethylated signals were provided by Illumina together with a technical p-value.

\section{Data analysis}

1) Selection of biomarker candidates on the microarray data: we first flagged the features on the array that did not pass the quality score recommended by the manufacturer; the number of non-flagged was higher in tissues (1300 to 1400) than in serum (1200 to 1400) or stools (1000 to 1200). Hierarchical clustering analysis revealed a striking difference in methylation between specimens taken from normal colonoscopy individuals and those from cancer patients, for both tissues and effluent samples. To investigate the results at the simple locus level, we proceeded as follows: we computed the averages of each locus' methylation values across all samples for tissue and stool in each category of normal $(\mathrm{N})$ and cancer $(\mathrm{Ca})$ individuals; for blood, we retained the value provided by Illumina for the single pooled sample assayed. Differences $(\mathrm{Ca}-\mathrm{N})$ between cancer and normal tissues or milieus were computed and the results were ranked according to Ca-N. Then for each of tissue, serum and stool we selected the most differentially methylated loci by taking the top decile in the Ca-N ranked differences. We performed cross comparisons between the three lists so obtained by intersecting those lists. We found $5 \mathrm{CpG}$ loci in the three-wise intersection, above the number expected (p_val 0.019).

2) Performance for CRC discrimination of combined NPY/PENK/WIF1: we computed a cumulative methylation index (CMI) consisting in the sum of the three methylation values for each sample and used it as a varying threshold for constructing a ROC curve. Specificity is calculated as the number of true negatives divided by the number of true negatives plus false positives. Sensitivity is calculated as the number of the true positives divided by the number of true positives plus false negatives. NPV is calculated as the number of the true negatives divides by the number of true negatives plus false negatives. PPV is calculated as the number of the true positives divided by the number of true positives plus false positives.

\section{Results}

Selection of candidate biomarkers by DNA methylation-array To screen for candidate biomarkers, we carried out a microarray study on tissue, serum and stool samples. We found 5 CpG loci, distributed among 4 genes in the intersection of the most differentially methylated loci; we selected PENK and NPY in that gene set (Additional file 3: Figure S1). We brought those two genes, together with WIF, into a QM-MSP assay for evaluation and clinical validation.

\section{Verification of DNA promoter methylation status by bisulfite sequencing}

Both methylated and unmethylated alleles were identified and fully characterized in a series of 12 PCR products through a bi-directional sequencing process and specific forward and reverse primers that did not contain $\mathrm{CpG}$ sites (Additional file 2: Table S2). As illustrated for WIF1 marker, sequencing results revealed that all $\mathrm{CpG}$ covering the amplicon in tumor samples were uniformly methylated. By contrast, in adjacent normal tissues all CpG were uniformly unmethylated showing the presence of thymidine nucleotides instead of cytosine on CpG sites, which suggests that bisulfite induced conversion (Additional file 4: Figure S2).

\section{Efficiency and specificity of the real-time QM-MSP assay}

We evaluated the performance of two different PCR-based assays, quantitative singleplex-MSP (QS-MSP) and quantitative multiplex-MSP (QM-MSP), in order to quantify the methylation levels of NPY, PENK, and WIF1. For co-amplifying two methylation-specific DNA targets in real-time, we used the associations of Fam/Vic and Ned/Vic fluorophore probes as each probe presents a strong individual spectral intensities with limited 
overlapping absorption spectra. We compared QS-MSP and QM-MSP to determine which assay agreed best with the detection thresholds $(\mathrm{Ct})$ on a serial dilution experiment from $10 \mathrm{ng}$ to $10 \mathrm{pg}$ of methylated DNA. Both QSMSP and QM-MSP gave similar cycle threshold $(\mathrm{Ct})$ values for each dilution point (data not shown) with similar high amplification efficiency (Figure 2A, 2B).

\section{QM-MSP assays in paired normal and tumor tissues}

We used two multiplex assays, namely Alb-Fam/WIF1-Vic and the NPY-Ned/PENK-Vic, to measure methylation of our three biomarkers in a set of 15 paired normal and tumor tissue samples. We set thresholds for the levels of methylation of, respectively, $25 \%$ for NPY, $17 \%$ for PENK, and 7\% for WIF1 and obtained the following corresponding performances: NPY displayed $100 \%$ sensitivity (Se) and 100\% specificity (Sp), PENK displayed $80 \% /$ 93.3\%, and WIF1 displayed $73.3 \% / 93.3 \%$, respectively (Additional file 5: Table S3). The sum of all methylation values across the three genes or cumulative methylation index (CMI), ranged between $2 \%$ and $58 \%$ in adjacent normal tissues and was greater or equal to $99 \%$ in carcinoma tissues (Figure $3 \mathrm{~A})$. The mean values $( \pm \mathrm{SD})$ of $\mathrm{CMI}$ in adjacent normal tissues $(15.07 \pm 16.60)$ were significantly lower than those in carcinoma tissues $(190.57 \pm 77.65$; $\mathrm{p}<0.0001$, Student-test; Figure 3). With a CMI threshold of $58 \%$, a Se of $100 \%$ (15 of 15) and a Sp of $100 \%$ (15 of 15 ) were obtained (Additional file 5: Table S3) and no significant differences of CMI related to the stages of carcinoma could be observed according to TNM staging: $156.74 \pm$ 83.96 for stages I/II and $213.14 \pm 68.66$ for stages III/IV $(P=0.09$, Student-test; Figure 3B).

\section{Validation of QM-MSP test in the sera for the detection of CRC}

We measured NPY, PENK and WIF1 by QM-MSP on two hundred and sixty six serum samples and assayed the discrimination power of their CMI. The set of samples consisted in a preliminary clinical set (Series 1 ) that included 49 individuals (30 presenting with normal colonoscopy, 10 with large adenomatous polyps and 9 with CRC) and in a second clinical set (Series 2) including 170 individuals (131 presenting with normal colonoscopy, 23 with CRC, 16 with large polyp adenomatous) (Table 2 ).

CMI values were used for calculating the Specificity $(\mathrm{Sp})$ versus the Sensitivity (Se) depending on various thresholds and the ROC (Receiver Operating Characteristic) diagrams were constructed. For each of the two series, we obtained similar ROC profiles for CRC detection (Figure 4A, 4B). To highlight key trade-offs between Se
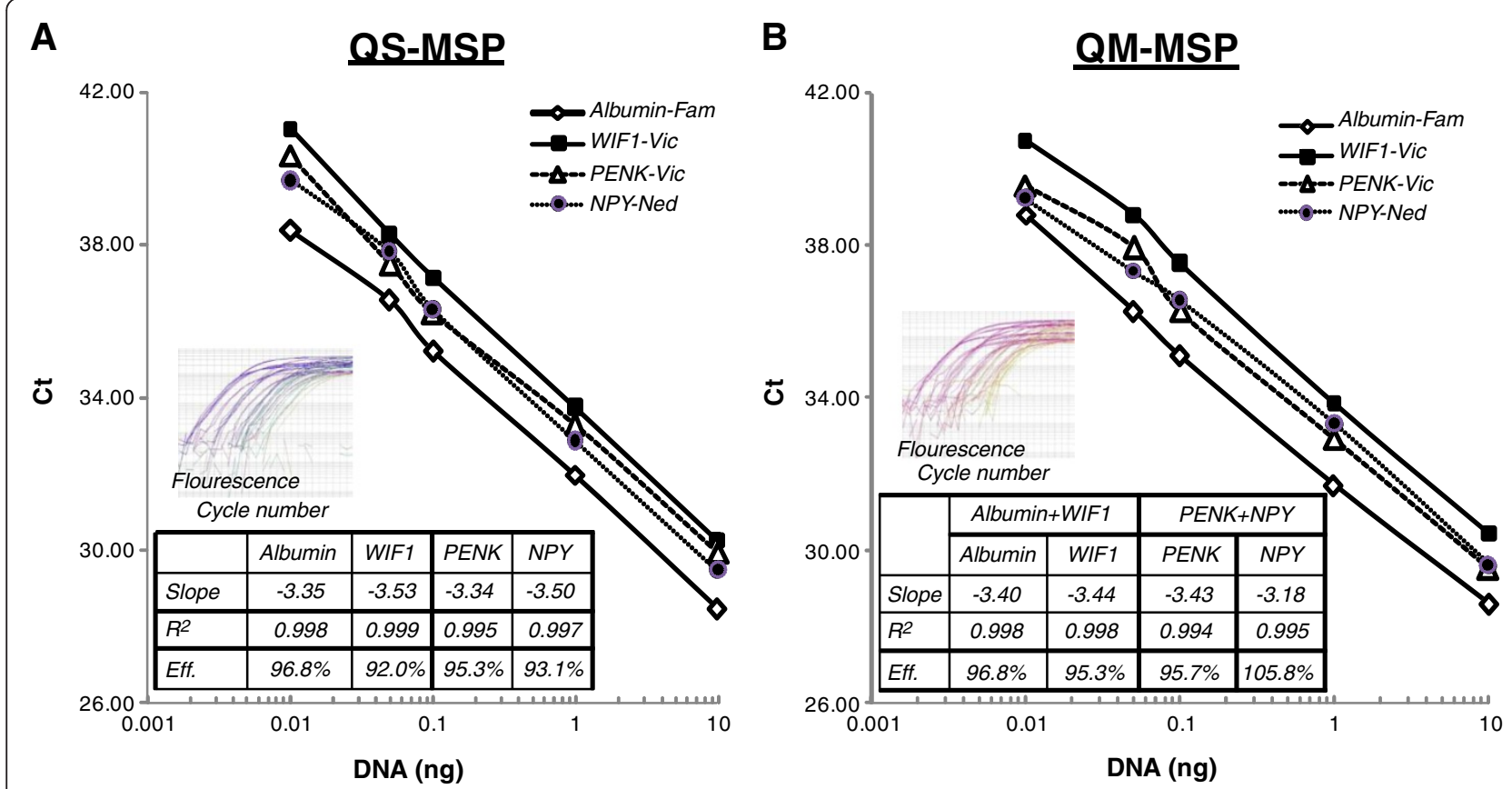

Figure 2 Efficiency of quantitative simplex (QS) and multiplex (QM) methylation-specific PCR. The diagrams illustrate comparison of both methods, namely $\mathbf{A}$ : quantitative multiplex methylation-specific PCR (QM-MSP) and $\mathbf{B}$ : quantitative singleplex methylation-specific PCR (QS-MSP). The reactions have been performed in duplicate. We used a mixture of primers and hydrolysis methylated probe specific to only amplify methylated alleles of Albumin, WIF1, PENK, and NPY genes along with a titration of human genomic DNA at various concentrations ranging from $10 \mathrm{up}$ to $0.01 \mathrm{ng} /$ well. On each dilution, the cycle threshold (Ct) was determined for standard DNA. Nearly identical Ct values for each DNA dilution indicate uniform primer performance over 3 logs. The slope of -3.32 (100\% efficiency) reflects a 2-fold amplification of DNA per cycle corresponding to a high efficiency. The correlation coefficient $R^{2}$ of 0.99 shows a high degree of linearity over the entire range. 


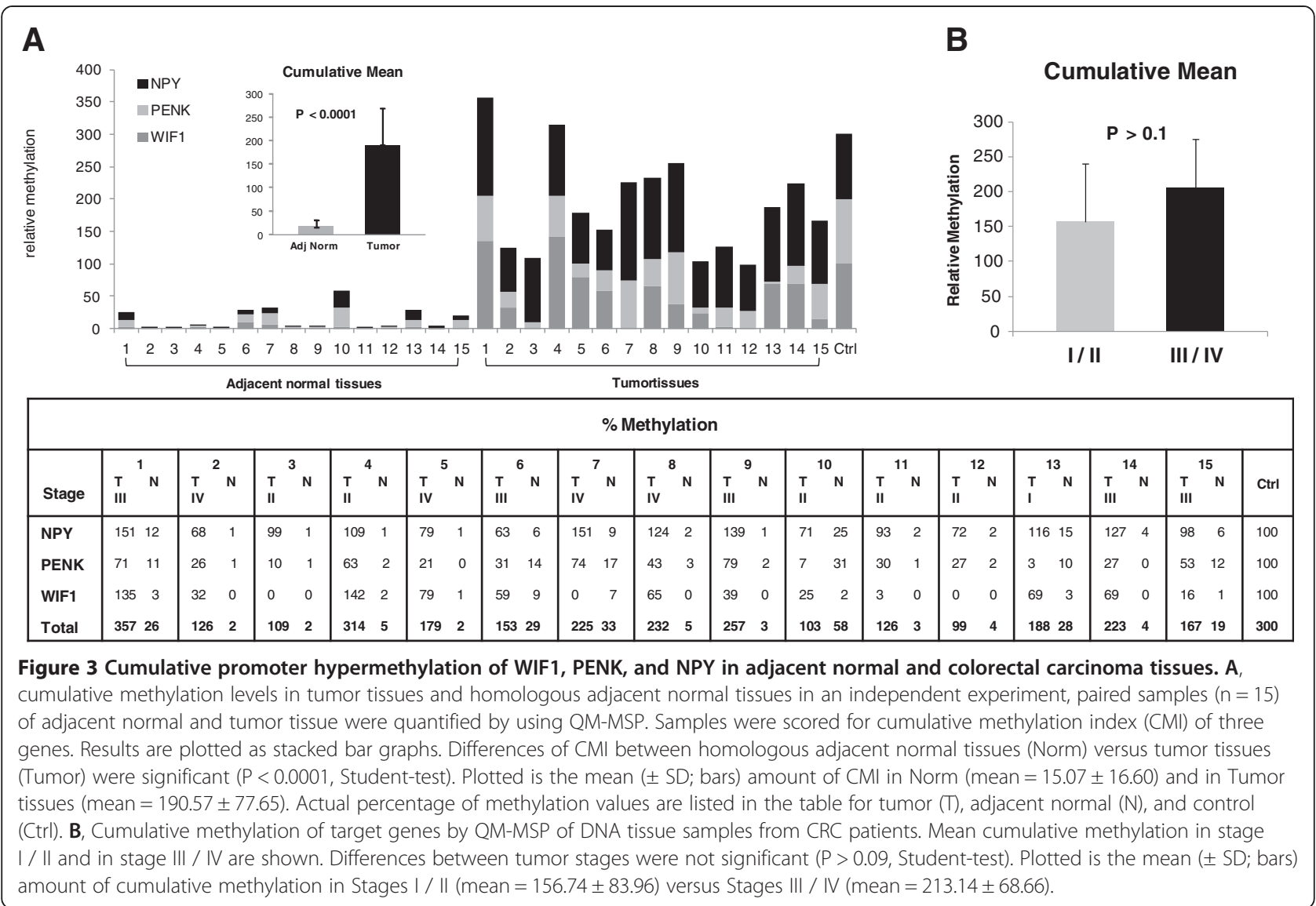

and Sp, we consider CMI thresholds for having high Se (e.g. Se about $90 \%$ ) and high Sp (e.g. Sp about $90 \%$ or Sp about 95\%). So, pooling the two series (Figure 4C), we obtain sensitivity/specificity figures of, respectively, 87\%/80\%, 78\%/90\% and 59\%/95\% (Table 3), and NPV/PPV figures of $97 \% / 47 \%, 95 \% / 61 \%$ and $92 \% / 70 \%$ (as computed without factoring the prevalence, since the population is already symptomatic). No significant relationship could be identified between serum CMI rates and TNM staging (Additional file 6: Figure S3).

\section{QM-MSP test in the sera for testing other cancers}

To assess the specific relevance of our gene panel to CRC we assayed in the same way forty seven serum samples from patients with cancers other than CRC obtaining sensitivity/specificity values of, e.g., $89 \% / 25 \%, 43 \% / 80 \%$ and $28 \% / 91 \%$ (Figure 3D).

\section{Discussion}

Here, we have shown that methylation profiling based on beadchip arrays is an effective method for selecting the genes with promoter methylation (i.e. NPY and PENK). Using our QM-MSP, we found a significant difference in the methylation levels of NPY, PENK, and WIF1 between
CRC and normal tissue and sera. On serum, the test performs CRC detection with sensitivity/specificity values of $87 \% / 80 \%$ (higher sensitivity) or $78 \% / 90 \%$, and $59 \% / 95 \%$ (higher specificity).

Epigenetic abnormalities leading to gene silencing, are a common occurrence in many malignancies [32]. They can be considered as a way to modulate gene activity, alternative or complementary way to gene mutations. The Wnt signaling pathway is critical for the regulation of colonic crypt renewal and homeostasis [33].The deregulation of crypt homeostasis, together with the loss of APC function by mutations, is known to initiate colorectal carcinogenesis [34,35]. In the epigenetic field, a large number of studies have suggested that promoter methylation-induced silencing of Wnt pathway antagonist genes constitute an "epigenetic gatekeeper", leading to constitutive Wnt signaling in many cancers [36] and colorectal cancer $[37,38]$ with many CpG islands reportedly affected in both tumors and in pre-cancerous lesions [39].

We have focused on the Wnt antagonist gene WIF1 (Wnt inhibitor factor 1) because it has been reported that the epigenetic silencing of this gene induces an aberrant activation of the Wnt signaling pathway in many cancers. This gene encodes a secreted Wnt antagonist 
A

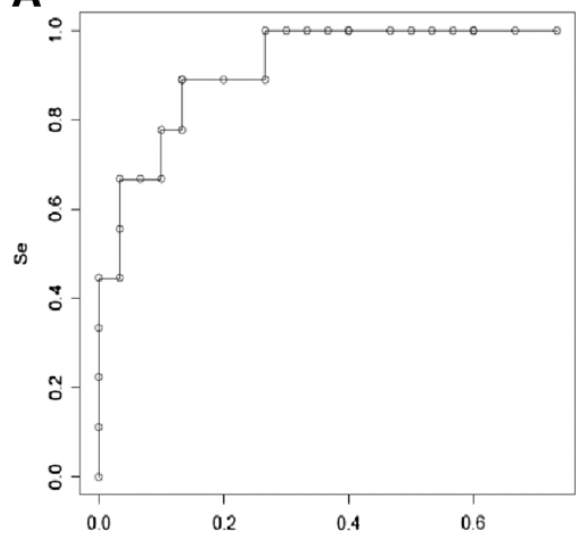

C

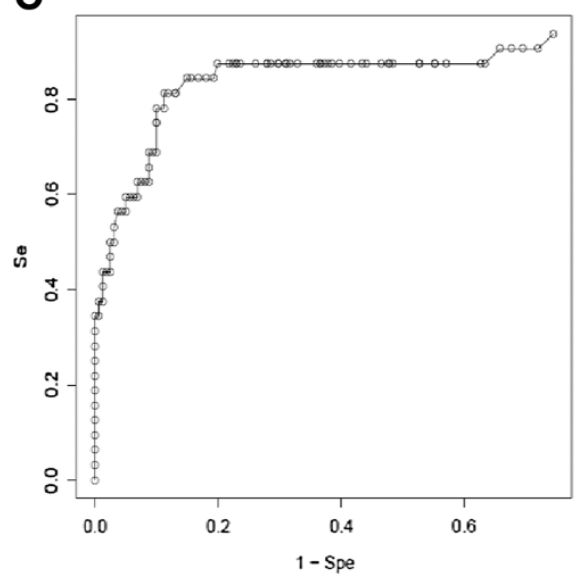

B

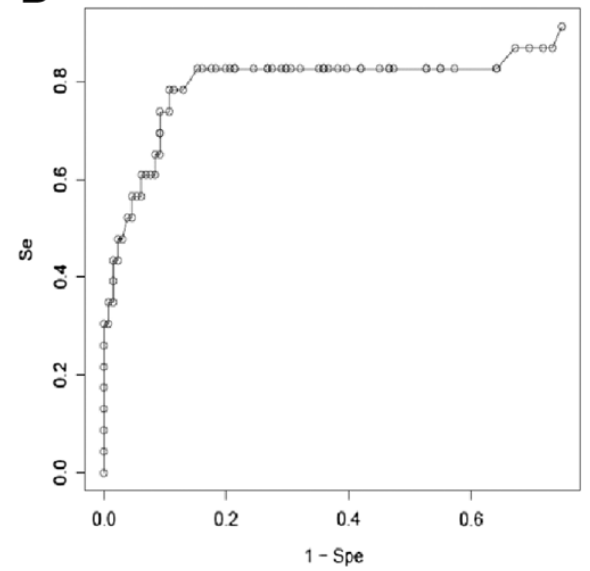

D

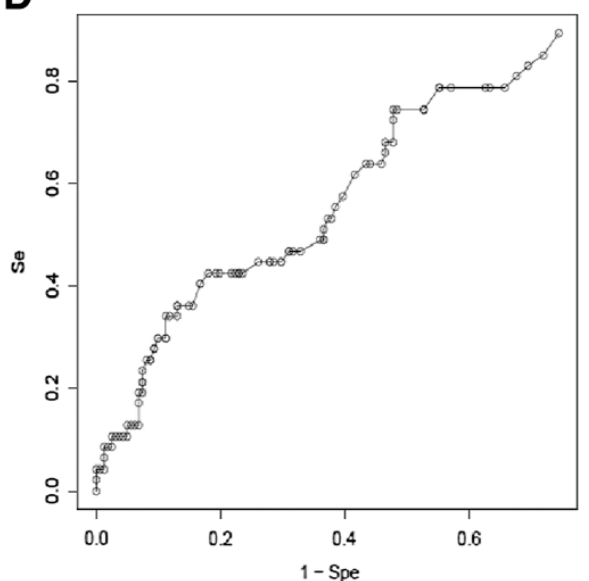

Figure 4 ROC curve relative to the cumulative methylation index. Sum of three (WIF1, NPY, PENK) methylation indexes are used to establish ROC curves corresponding to Series 1 (A), Series 2 (B), total of both series (C) for CRC and Series 3 (D) for other cancers.

sequestering secreted Wnt proteins and inhibits their activities, limiting carcinogenesis in human [19,20]. Loss of WIF1 expression leads to aberrantly activate Wnt signaling, which is associated with cancer and could act as a tumor suppressor gene [21,22]. WIF1 expression was found to be frequently down-regulated in hepatocellular carcinoma; this down-regulation could be attributed to hypermethylation of the WIF1 promoter [23]. In osteosarcomas, silencing of WIF1 by promoter hypermethylation was associated with loss of differentiation and increased proliferation [24]. Recent studies demonstrate that the WIF1 gene is down-regulated or silenced in astrocytomas [25], the most common tumors of the central nervous system, and in cervical cancer [26], both by aberrant promoter methylation. WIF1 was reported as frequent target of epigenetic inactivation in several tumors such as lung, prostate, breast, bladder cancers [27-29]. In glioblastomas, WIF1 silencing is mediated by genomic deletion, promoter methylation, or both [30]. The WIF1 gene promoter hypermethylation has been reported in circulating DNA isolated from plasma of colorectal adenoma and CRC patients [31].

We presumed that WIF1 could be considered as a target for epigenetic silencing in CRC. Our results from tissues and effluents were consistent with this hypothesis. However, WIF1 alone could not be considered as a unique marker for cancer detection, from effluents, although its discriminative value in tissues was very high. This is the reason why we investigated a larger panel including various other genes. Accordingly, we used Illumina methylated microarray as a genome-wide screening tool for finding hypermethylated genes in CRC and normal colonoscopy patients' effluents and characterized a panel of less than ten genes including NPY and PENK, which are known to be involved in gastrointestinal tract functions particularly in nutriment uptake and absorptions.

Neuropeptide Y (NPY), a neurotransmitter, acts on the central nervous system as a potent appetite stimulator controlled by the feedback action of both leptin from adipose tissue and ghrelin from the stomach $[40,41]$. These 
Table 3 Cumulative promoter hypermethylation of WIF1, PENK, and NPY DNA in serum

\begin{tabular}{lccc}
\hline & CMI & Specificity & Sensitivity \\
\hline Series 1 & 0.62 & $73(22 / 30)$ & $100(9 / 9)$ \\
& $0.68-0.75$ & $>80$ & $>80$ \\
& 1.15 & 90 & 66 \\
Series 2 & 2.85 & 95 & 66 \\
& 0.01 & $25(33 / 131)$ & $91(21 / 23)$ \\
& $0.60-0.73$ & $>80$ & $>80$ \\
& 0.94 & 90 & 75 \\
Pooled 1+2 & 2.48 & 96 & 52 \\
& 0.05 & $34(55 / 161)$ & $94(30 / 32)$ \\
& $0.62-0.85$ & $>80$ & $>80$ \\
& 0.94 & 90 & 75 \\
& 2.01 & 95 & 59 \\
\hline
\end{tabular}

Sensitivity (Se) and Specificity (Sp) are shown at several CMI thresholds for both CRC series: $\mathrm{Se}>90 \%(\mathrm{CMI}=0.62$ for Series 1 and 0.01 for Series 2), Sp > $90 \%$ (1.15 and 0.94$)$ and $\mathrm{Sp}>95 \%$ (2.85 and 2.48). We note the existence of two similar numerical ranges for the thresholds $(0.68-0.75$ for Series 1 and $0.60-0.73$ for Series 2 ) where both Sp and Se are high (>80\%). CMI values are the cumulative methylation index of three genes.

two peptides are involved in obesity and metabolic syndrome, two conditions clearly increasing the risk of cancers particularly the colon cancer [42]. NPY is involved in cell motion and cell proliferation as well as neuropeptide hormone activity [43]. NPY can reduce the invasive potential of colon cancer cells in vitro [44]. In prostate cancer, the decrease of NPY expression is associated with aggressive clinical behavior [45]. In other studies, NPY was shown to be frequently hypermethylated in neuroblastomas [46], hepatocellular carcinoma tissues [47] and their promoter hypermethylation was correlated with inactivation of gene expression. More recently, DeMorrow and colleagues have demonstrated that the treatment of cholangiocarcinoma cells with NPY as well as in vitro and in vivo decreases both proliferation and migration [48]. The present study reports the evidence of NPY gene involvement in CRC. Although further investigations are required to understand whether hypermethylation is a cause or a consequence of carcinogenesis, it is suggested here to use hypermethylated gene as a blood-based marker.

Proenkephalin (PENK), was originally shown to be expressed in the mature nervous and neuroendocrine systems through opioid pathway, in the regulation of cell death and survival [49]. PENK protein has been shown to act as apoptotic activator particularly under chemotherapy drugs in colon cancer [50,51]. Its expression being down-regulated by Fos and Jun, two protooncogenes [52]. PENK was reported to be down-regulated in prostate cancer [53]. PENK is frequently methylated in bladder [54], and pancreatic cancer [55-57]. Although, no study has so far established a direct link between the PENK promoter hypermethylation and the development of CRC, our findings suggest that this gene is frequently hypermethylated in CRC patients' effluents and might be a valuable biomarker for its detection.

Main advantages of our QM-MSP are an analysis of several gene performed in a single process and a quantification of methylation allowing optimal balancing between sensitivity and specificity. Our clinical study shows that the variation of methylation threshold could offer of tests for diagnosis as well as surveillance of recurrences of CRC. For example, a CMI threshold of 0.05 appears to be more appropriate for diagnosis/monitoring purposes, yielding high sensitivity, detecting the real cancers; a CMI of 2 sets our selection in the higher range of specificity, so limiting the number of unnecessary colonoscopies. We also showed relevance of our gene panel for detecting non colon cancers in a series of 47 patients' samples, where we obtained sensitivity/specificity of, e.g., $89 \% / 25 \%, 43 \% / 80 \%$ and $28 \% / 91 \%$. However, a limitation of the proposed test is the low rate of adenomatous detection, making it necessary to establish the optimal periodicity for performing the test.

\section{Conclusions}

In this paper we show data indicating that combining the methylation values of NPY, PENK, and WIF1 is potentially useful as a sensitive and specific blood test for identifying among individuals with digestive symptoms, those individuals for whom colonoscopy is recommended. This test, if validated, could be proposed as a cost effective non invasive screening tool for the selection of asymptomatic cancer patients for colonoscopy. The results for other cancers suggest a possible second use for the test for patients who would be positives to the test and negative to colonoscopy, indicating that might undergo other cancer-specific examinations.

\section{Additional files}

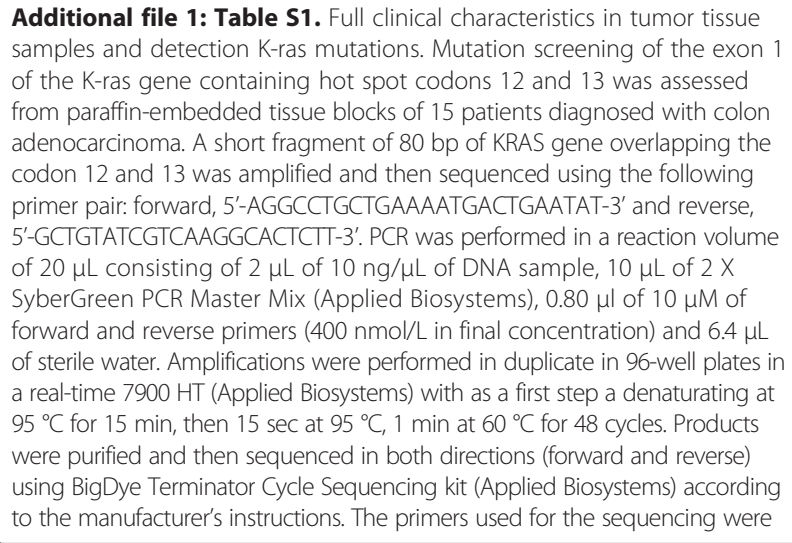

Additional file 1: Table S1. Full clinical characteristics in tumor tissue samples and detection K-ras mutations. Mutation screening of the exon 1 of the K-ras gene containing hot spot codons 12 and 13 was assessed from paraffin-embedded tissue blocks of 15 patients diagnosed with colon adenocarcinoma. A short fragment of $80 \mathrm{bp}$ of KRAS gene overlapping the codon 12 and 13 was amplified and then sequenced using the following primer pair: forward, 5'-AGGCCTGCTGAAAATGACTGAATAT-3' and reverse, 5'-GCTGTATCGTCAAGGCACTCTT-3'. PCR was performed in a reaction volume of $20 \mu \mathrm{L}$ consisting of $2 \mu \mathrm{L}$ of $10 \mathrm{ng} / \mu \mathrm{L}$ of DNA sample, $10 \mu \mathrm{L}$ of $2 \mathrm{X}$ SyberGreen PCR Master Mix (Applied Biosystems), $0.80 \mu \mathrm{l}$ of $10 \mu \mathrm{M}$ of forward and reverse primers $(400 \mathrm{nmol} / \mathrm{L}$ in final concentration) and $6.4 \mathrm{\mu L}$ of sterile water. Amplifications were performed in duplicate in 96-well plates in a real-time $7900 \mathrm{HT}$ (Applied Biosystems) with as a first step a denaturating at $95^{\circ} \mathrm{C}$ for $15 \mathrm{~min}$, then $15 \mathrm{sec}$ at $95^{\circ} \mathrm{C}, 1 \mathrm{~min}$ at $60^{\circ} \mathrm{C}$ for $48 \mathrm{cycles}$. Products were purified and then sequenced in both directions (forward and reverse) using BigDye Terminator Cycle Sequencing kit (Applied Biosystems) according to the manufacturer's instructions. The primers used for the sequencing were 
identical to those used for the PCR. The sequence reactions were run and analyzed on an ABI 3100 Genetic Analyzer (Applied Biosystems).

Additional file 2: Table S2. Oligonucleotides.

Additional file 3: Figure S1. Selection of candidate biomarkers by DNA methylation-array. Left: Venn diagram. Urine, Serum and Tissue lists obtained by taking the top decile in the ranked Ca-N lists. Right: Loci Illumina goldengate IDs.

Additional file 4: Figure S2. The bisulfite sequence of the WIF1 promoter. Representative bisulfite sequencing electrophoregram of the WIF1 promoter verifies methylation status assessed by QS-MSP from carcinoma colorectal (Tumor) and adjacent normal tissues (Adj Norm). The diagram above illustrates one of the 15 samples of tumor tissues; cytosine nucleotides underlined in black remain unchanged indicating all sites are methylated in the amplicon product. By contrast, in the homologous normal tissue, only thymidine nucleotides underlined in red are detected instead of cytosine residues due to bisulfite modified DNA which is indicative of unmethylated amplicon products. It is interesting to note that comparison of two sequences of normal and tumoral tissues indicates that all cytosine at non-CpG sites are converted to thymine resulting entirely from DNA modification. This follows after sodium bisulfite treatment when referring to the wild-type WIF1 gene sequence.

Additional file 5: Table S3. Gene promoter analysis in adjacent normal and tumor tissues. Optimal threshold values obtained for simple gene and in combination of 3 genes. Taking into account the different degrees of methylation, we set threshold of $\mathrm{CMl}$ at $58 \%$ to obtain the highest performance in terms of sensitivity and specificity.

Additional file 6: Figure S3. Methylation correlated in stages of CRC. Mean cumulative methylation in I / II and III / IV stages of CRC serum samples. Differences between both stages were not significant $(P>0.1$, Student-test). Plotted is the mean ( \pm SD; bars) amount of cumulative methylation in I / II stages with mean $=44.40 \pm 78.53$, versus in III / IV stages with mean $=33.55 \pm 61.71$.

\section{Competing interests}

Authors do not have any competing interests for writing this article. JP Roperch is an employee, and I. Sobhani is the main scientific consultant of Company Profilome SAS, Paris,

\section{Authors' contributions}

Participated in research design: All authors. Conducted experiments: JPR, RL, SF, FLB, and IS. Performed data analysis: JPR and RI. Wrote or Contributed to the writing of the manuscript: JPR, RI, and IS. All authors read and approved the final manuscript to be published.

\section{Acknowledgements}

Bruno Costes, Karen Leroy, Jeanne Tran Van Nhieu, Michael Levy, Christophe Tournigand. Group of doctors from lle de France who contributed to the enrolment of individuals (Thomas Aparicio, Elie Zrhien, Maryan Cavicchi, Yann Lebaleur, Christophe Locher, Hervé Hagège, Robert Benamouzig, Mireille Petit, Dominique Gilot, Gilles Trodjman, Michelle Algard, Françoise Uzan, Marc Prieto, Claude Altman).

\section{Grant support}

This research work has been funded by the French National Research Agency (ANR) and ACD (Association Charles Debray).

\footnotetext{
Author details

'Profilome SAS, Paris Biotech 24 rue du Faubourg St Jacques, Paris 75014, France. ${ }^{2}$ King Abdullah University of Science and Technology (KAUST), Biosciences Core Laboratory, Thuwal 23955-6900, Saudi Arabia. ${ }^{3}$ Laboratoire d'Investigation Clinique (LIC), Henri Mondor Hospital \& University Paris-Est, Créteil, France. ${ }^{4}$ Department of Gastroenterology and Medical Oncology, Henri Mondor Hospital, Créteil, France. ${ }^{5}$ Department of Clinical Oncology, Henri Mondor Hospital, Créteil, France. ${ }^{6}$ Department of Surgery, Henri Mondor Hospital, Créteil, France.
}

Received: 5 August 2013 Accepted: 25 November 2013

Published: 1 December 2013

\section{References}

1. Parkin DM, Bray F, Ferlay J, Pisani P: Estimating the world cancer burden: Globocan 2000. Int J Cancer 2001, 94(2):153-156.

2. Boyle P, Leon ME: Epidemiology of colorectal cancer. Br Med Bull 2002, 64:1-25.

3. Jemal A, Siegel R, Xu J, Ward E: Cancer Statistics, 2010. Cancer J Clin 2010, 60(5):277-300

4. Winawer S, Fletcher R, Rex D, Bond J, Burt R, Ferrucci J, et al: Colorectal cancer screening and surveillance: clinical guidelines and rationale-update based on new evidence. Gastroenterology 2003, 124(2):544-560.

5. Osborn NK, Ahlquist DA: Stool screening for colorectal cancer: molecular approaches. Gastroenterology 2005, 128(1):192-206.

6. Sobhani I, Alzahouri K, Ghout I, Charles DJ, Durand-Zaleski I: Cost-effectiveness of mass screening for colorectal cancer: choice of fecal occult blood test and screening strategy. Dis Colon Rectum 2011, 54(7):876-886.

7. Faivre J, Dancourt V, Lejeune C, Tazi MA, Lamour J, Gerard D, et al: Reduction in colorectal cancer mortality by fecal occult blood screening in a French controlled study. Gastroenterology 2004, 126(6):1674-1680.

8. Frazier AL, Colditz GA, Fuchs CS, Kuntz KM: Cost-effectiveness of screening for colorectal cancer in the general population. JAMA 2000, 284(15):1954-1961.

9. Desch CE, Benson AB, Somerfield MR, Flynn PJ, Krause C, Loprinzi $C L$, et al: Colorectal cancer surveillance: 2005 update of an American society of clinical oncology practice guideline. J Clin Oncol 2005, 23(33):8512-8519.

10. Mandel JS, Bond JH, Church TR, Snover DC, Bradley GM, Schuman LM, et al: Reducing mortality from colorectal cancer by screening for fecal occult blood: Minnesota colon cancer control study. N Engl J Med 2005, 328(19):1365-1371.

11. Clerc L, Jooste V, Lejeune C, Schmitt B, Arveux P, Quantin C, et al: Cost of care of colorectal cancers according to health care patterns and stage at diagnosis in France. Eur J Health Econ 2008, 9(4):361-367.

12. Hardcastle JD, Thomas WM, Chamberlain J, Pye G, Sheffield J, James PD, et al: Ramdomised, controlled trial of faecal occult blood screening for colorectal cancer: results for first 107,349 subjects. Lancet 1989, 1(8648):1160-1164

13. Esteller M: DNA methylation and cancer therapy: new developments and expectations. Curr Opin Oncol 2005, 17(1):55-60.

14. Baylin SB, Esteller M, Rountree MR, Bachman KE, Schuebel K, Herman JG: Aberrant patterns of DNA methylation, chromatin formation and gene expression in cancer. Hum Mol Genet 2001, 10(7):687-692.

15. Wong JJ, Hawkins NJ, Ward RL: Colorectal cancer: a model for epigenetic tumorigenesis. Gut 2007, 56(1):140-148.

16. Muller HM, Widschwendter M: Methylated DNA as a possible screening marker for neoplastic disease in several body fluids. Expert Rev Mol Diagn 2003, 3(4):443-458.

17. Fackler MJ, Malone K, Zhang Z, Schilling E, Garrett-Mayer E, Swift-Scanlan T, et al: Quantitative multiplex methylation-specific PCR analysis doubles detection of tumor cells in breast ductal fluid. Clin Cancer Res 2006, 12(11 Pt 1):3306-3310.

18. Hoque MO, Begum S, Topaloglu O, Chatterjee A, Rosenbaum E, Van CW, et al: Quantitation of promoter methylation of multiple genes in urine DNA and bladder cancer detection. J Natl Cancer Inst 2006, 98(14):996-1004.

19. Hsieh JC, Kodjabachian L, Rebbert ML, Rattner A, Smallwood PM, Samos CH, et al: A new secreted protein that binds to Wnt proteins and inhibits their activities. Nature 1999, 398(6726):431-436.

20. He B, Reguart N, You L, Mazieres J, Xu Z, Lee AY, et al: Blockade of Wnt-1 signaling induces apoptosis in human colorectal cancer cells containing downstream mutations. Oncogene 2005, 24(18):3054-3058.

21. Taniguchi H, Yamamoto H, Hirata T, Miyamoto N, Oki M, Nosho K, et al: Frequent epigenetic inactivation of Wnt inhibitory factor-1 in human gastrointestinal cancers. Oncogene 2005, 24(53):7946-7952

22. Cebrat M, Strzadala L, Kisielow P: Wnt inhibitory factor-1: a candidate for a new player in tumorigenesis of intestinal epithelial cells. Cancer Lett 2004, 206(1):107-113.

23. Ding Z, Qian YB, Zhu LX, Xiong QR: Promoter methylation and mRNA expression of DKK-3 and WIF-1 in hepatocellular carcinoma. World J Gastroenterol 2009, 15(21):2595-2601.

24. Kansara M, Tsang M, Kodjabachian $L$, Sims NA, Trivett MK, Ehrich $M$, et al: Wnt inhibitory factor 1 is epigenetically silenced in human osteosarcoma, and targeted disruption accelerates osteosarcomagenesis in mice. Clin Invest 2009, 119:837-851. 
25. Yang Z, Wang Y, Fang J, Chen F, Liu J, Wu J: Expression and aberrant promoter methylation of Wnt inhibitory factor-1 in human astrocytomas. J Exp Clin Cancer Res 2010, 29:26.

26. Delmas AL, Riggs BM, Pardo CE, Dyer LM, Darst RP, Izumchenko EG, et al: WIF1 is a frequent target for epigenetic silencing in squamous cell carcinoma of the cervix. Carcinogenesis 2011, 32(11):1625-1633.

27. Wissmann C, Wild PJ, Kaiser S, Roepcke S, Stoehr R, Woenckhaus M, et al: WIF1, a component of the Wnt pathway, is down-regulated in prostate, breast, lung, and bladder cancer. J Pathol 2003, 201:204-212.

28. Mazieres J, He B, You L, Xu Z, Lee AY, Mikami I, et al: Wnt inhibitory factor-1 is silenced by promoter hypermethylation in human lung cancer. Cancer Res 2004, 64(14):4717-4720

29. Veeck J, Wild PJ, Fuchs T, Schuffler PJ, Hartmann A, Knüchel R, Dahl E: Prognostic relevance of Wnt-inhibitory factor-1 (WIF1) and Dickkopf-3 (DKK3) promoter methylation in human breast cancer. BMC cancer 2009 9:217.

30. Lambiv WL, Vassallo I, Delorenzi M, Shay T, Diserens AC, Misra A, et al: The Wnt inhibitory factor 1 (WIF1) is targeted in glioblastoma and has a tumor suppressing function potentially by induction of senescence. Neuro Oncol 2011, 13(7):736-747.

31. Lee BB, Lee EJ, Jung EH, Chun HK, Chang DK, Song SY, et al: Aberrant methylation of APC, MGMT, RASSF2A, and Wif-1 genes in plasma as a biomarker for early detection of colorectal cancer. Clin Cancer Res 2009, 15(19):6185-6191.

32. Jones PA: DNA methylation and cancer. Oncogene 2002, 21(35):5358-5360.

33. Byun T, Karimi M, Marsh JL, Milovanovic T, Lin F, Holcombe RF: Expression of secreted Wnt antagonists in gastrointestinal tissues: potential role in stem cell homeostasis. J Clin Pathol 2005, 58:515-519.

34. Powell SM, et al: APC mutations occur early during colorectal tumorigenesis. Nature 1992, 359:235-237.

35. Sansom OJ, et al: Loss of Apc in vivo immediately perturbs Wnt signaling, differentiation, and migration. Genes Dev 2004, 18:1385-1390.

36. Logan $C Y$, Nusse R: The Wnt signaling pathway in development and disease. Annu Rev Cell Dev Biol 2004, 20:781-810.

37. Segditsas S, Tomlinson I: Colorectal cancer and genetic alterations in the Wnt pathway. Oncogene 2006, 25(57):7531-7537.

38. Gregorieff A, Pinto D, Begthel H, Destree O, Kielman M, Clevers H: Expression pattern of Wnt signaling components in the adult intestine. Gastroenterology 2005, 129(2):626-638.

39. Chan $A O$, Rashid $A: C p G$ island methylation in precursors of gastrointestinal malignancies. Curr Mol Med 2006, 6:401-408.

40. Kalra SP, Kalra PS: Neuropeptide Y: a physiological orexigen modulated by the feedback action of ghrelin and leptin. Endocrine 2003, 22(1):49-56

41. Ukkola O, Ravussin E, Jacobson P, Perusse L, Rankinen T, Tschop M, et a Role of ghrelin polymorphisms in obesity based on three different studies. Obes Res 2002, 10(8):782-791.

42. Renehan AG, Tyson M, Egger M, Heller RF, Zwahlen M: Body-mass index and incidence of cancer: a systematic review and meta-analysis of prospective observational studies. Lancet 2008, 371(9612):569-578.

43. Hallden G, Hadi M, Hong HT, Aponte GW: Y receptor-mediated induction of CD63 transcripts, a tetraspanin determined to be necessary for differentiation of the intestinal epithelial cell line, hBRIE 380i cells. J Biol Chem 1999, 274:27914-27924.

44. Ogasawara M, Murata J, Ayukawa K, Saiki I: Differential effect of intestinal neuropeptides on invasion and migration of colon carcinoma cells in vitro. Cancer Lett 1997, 119:125-130.

45. Liu AJ, Furusato B, Ravindranath L, Chen YM, Srikantan V, McLeod DG, Petrovics G, Srivastava S: Quantitative analysis of a panel of gene expression in prostate cancer with emphasis on NPY expression analysis. J Zhejiang Univ Sci B 2007, 8:853-859.

46. Abe M, Watanabe N, McDonell N, Takato T, Ohira M, Nakagawara A, Ushijima T: Identification of genes targeted by $\mathrm{CpG}$ island methylator phenotype in neuroblastomas, and their possible integrative involvement in poor prognosis. Oncology 2008, 74:50-60.

47. Shin SH, Kim BH, Jang JJ, Suh KS, Kang GH: Identification of novel methylation markers in hepatocellular carcinoma using a methylation array. J Korean Med Sci 2010, 25(8):1152-1159.

48. DeMorrow $S$, Onori $P$, Venter J, Invernizzi $P$, Frampton $G$, White $M$ Franchitto $A$, et al: Neuropeptide $Y$ inhibits cholangiocarcinoma cell growth and invasion. Am J Physiol Cell Physiol 2011, 300(5):1078-1089.
49. Tegeder I, Geisslinger G: Opioids as modulators of cell death and survival-unraveling mechanisms and revealing new indications. Pharmacol Rev 2004, 56(3):351-369.

50. Bottger A, Spruce BA: Proenkephalin is a nuclear protein responsive to growth arrest and differentiation signals. J Cell Bio/ 1995, 130(6):1251-1262.

51. Mc Tavish N, Copeland LA, Saville MK, Perkins ND, Spruce BA: Proenkephalin assists stress-activated apoptosis through transcriptional repression of NF-KappaB and p53-related genes targets. Cell Death Differ 2007, 14(9):1700-1710.

52. Sonneberg JL, Rauscher FJ, Morgan Jl, Curran T: Regulation of proenkephalin by fos and Jun. Science 1989, 246(4937):1622-1625.

53. Goo YA, Goodlett DR, Pascal LE, et al: Stromal mesenchyme cell genes of the human prostate and bladder. BMC Urol 2005, 5:17.

54. Chung W, Bondaruk J, Jelinek J, Lotan Y, Liang S, Czerniak B, Issa JP: Detection of bladder cancer using novel DNA methylation biomarkers in urine sediments. Cancer Epidemiol Biomarkers 2011, 20(7):1483-1491.

55. Ueki T, Toyata M, Skinner H, et al: Identification and characterization of differentially methylated CpG islands in pancreatic carcinoma. Cancer Res 2001, 61(23):8540-8546.

56. Fukushima N, Sato N, Ueki T, et al: Aberrant methylation of preproenkephalin and p16 genes in pancreatic intraepithelial neoplasia and pancreatic ductal adenocarcinoma. Am J Pathol 2002, 160(5):1573-1581.

57. Tan AC, Jimeno A, Lin SH, Wheelhouse J, Chan F, Solomon A, et al: Characterizing DNA methylation patterns in pancreatic cancer genome. Mol Oncol 2009, 3(5-6):425-438

\section{doi:10.1186/1471-2407-13-566}

Cite this article as: Roperch et al:: Aberrant methylation of NPY, PENK, and WIF1 as a promising marker for blood-based diagnosis of colorectal cancer. BMC Cancer 2013 13:566.

\section{Submit your next manuscript to BioMed Central and take full advantage of:}

- Convenient online submission

- Thorough peer review

- No space constraints or color figure charges

- Immediate publication on acceptance

- Inclusion in PubMed, CAS, Scopus and Google Scholar

- Research which is freely available for redistribution 